Article

\title{
Effects of a Tariff Reduction on Grain Self-Sufficiency: Evidence from Country-Level Panel Data
}

\author{
Younghyeon Jeon ${ }^{1}$ and Byeong-il Ahn ${ }^{2, *}$ \\ 1 Korea Rural Economic Institute, Naju 58217, Korea; uouo1011@krei.re.kr \\ 2 Department of Food and Resource Economics, Korea University, Seoul 02841, Korea \\ * Correspondence: ahn08@korea.ac.kr; Tel.: +82-2-3290-3031
}

Received: 11 September 2017; Accepted: 7 October 2017; Published: 12 October 2017

\begin{abstract}
This paper investigates the effects of a tariff reduction on the grain self-sufficiency and the sustainability of domestic grain production. We develop a theoretical model in which trade, tariff, and supply-demand equations are explicitly included, with the classification of food importing and exporting countries. Estimation results based on panel data for 150 countries over 17 years show that the effects of domestic tariff of food-importing countries on the grain self-sufficiency rate (SSR) are positive. This implies that market expansion through tariff reduction will have a negative effect on the importing country's food SSR and sustainable domestic supply. Using the estimated coefficients on the empirical equations, we derived the elasticities of grain SSR with respect to the tariff rate of food-importing countries. Those are in the ranges of 0.221-0.387.
\end{abstract}

Keywords: trade liberalization; tariff reduction; self-sufficiency; system generalized method of moments; sustainable production

\section{Introduction}

The international trade of agricultural products significantly influences not only the livelihoods of millions of farmers across the world, but also most countries' food security strategies in which sustainable food supply is most important. World Bank, International Monetary Fund, and pro-liberalization trade advocates argue that trade liberalization leads to an increase in imports and a decrease in the price of imported products, thereby enhancing food security [1]. On the other side, however, it has been also pointed out that the benefit from the improvements in food security through agricultural trade liberalization is highly limited [2-4]. Trade liberalization through the reduction or removal of the import tariff has increased the demand for low-cost, imported agricultural products. At the same time, it has increased the dependency on food imports by drastically decreasing domestic food production and weakening the capacity of sustainable domestic food supply. The typical example is the wheat market in Korea. After the trade liberalization of wheat in 1983, the domestic production of wheat has dramatically decreased as the demand for imported wheat has increased rapidly. Therefore, the country has become entirely dependent on imported wheat [5-7] (self-sufficiency rate is less than $1 \%$ as of 2017). As a result, the sustainable supply of domestically produced wheat has become no longer possible. This is why the prices of wheat products in Korea dramatically increased when the world grain crisis occurred in 2008. A similar example is found for rice in Philippines. Further, many African countries that were traditionally food exporters have become food importers over the past 20 years [8]. As pointed by Clapp [9], a country whose staple grain is under the influence of a smaller number of foreign exporters or a country at risk of trade disruptions caused by a war or other political reasons would benefit from higher levels of food self-dependency. 
After the world grain crisis in 2008, concerns about food security have expanded in most of the countries that import food. Moreover, the problem of food insecurity is not only a concern for importers, but also for the entire world. In particular, food importing countries have been concerned about the sustainability of food supply. Therefore, importers and exporters began to set forth policies for securing the food self-sufficiency, since it has been regarded as one of the effective tools for achieving food security. However, trade liberalization through a tariff reduction has conflicting effects on food accessibility and availability (FAO defines food security using the indicators of "availability", "accessibility", "stability over time", and "utilization" [10]). In this context, this paper investigates the effects of a tariff and the factors that shift food supply and demand on the grain self-sufficiency, which is a main component in defining the food security, especially from the perspective of food-importing countries.

Food self-sufficiency and food sustainability are closely related [11,12]. The decline in the food self-sufficiency rate (SSR) means a decrease in domestic food production, which tends to result in the conversion of the agricultural land for industrial or other purposes, as we have seen in many developing countries. Therefore, once the self-sufficiency rate falls, the agricultural land which is the most important resource for food production, is likely to decrease, resulting in the difficulty of sustainable food supply within the country. This is because there is an irreversibility, which means a very high cost to restore agricultural land, when the land is converted to other uses [13-15]. In this sense, a recent study of Erokhin [12] has also used the food SSR as an indicator of sustainable domestic food supply.

On the other hand, if the food supply is dependent entirely on foreign countries due to the drop in the SSR, the impact from the overseas market such as a price spike in 2008 may lead to a sharp decline in food import. In this context, Little and Buchan [16] defined a sustainable market as a market in which self-sufficiency is maintained. Luan et al. [17] and Ahn and Han [18] pointed out that the economy of a country might have a difficulty in achieving a sustainable growth, if the food self-sufficiency is not maintained.

Many previous studies argue that tariff reduction is the main reason for the decrease in food SSR (For example, [19-21]). If food production is concentrated in a small number of exporting countries, it may be difficult for importing countries to obtain an adequate supply of food in the event of production shocks caused by climate change such as drought, therefore importing countries may be highly vulnerable to instability, as pointed out by O'Hagan [20], Suweis et al. [22], Puma et al. [23], MacDonald et al. [24], and Clapp [9]. On the other hand of course, there are apposite views regarding the free trade and self-sufficiency. For example, Naylor and Falcon [25] argue policies intended to maintain SSR are inefficient and lead to market distortion. Clapp [26] pointed out that whether food is produced domestically or imported from abroad does not matter in achieving food security.

With growing efforts to expand the market for agricultural products through trade, it is time to verify how trade liberalization through the tariff reduction will affect the SSR of the countries over the world. It is interesting and important to see whether exporting countries export more (and as a result, SSR increases) and importing countries import more (and as a result, SSR decreases) as tariffs are lowered, which implies the progress of polarization in food self-sufficiency and uneven sustainability conditions for domestic supply. Some previous studies have partially proven that the polarization of food self-sufficiency has maintained or continued $[23,27]$. However, these studies did not identify the causes of the polarization of food SSR. Therefore, the present study focuses on the reduction of tariffs as one of the most important factors in the polarization of food self-sufficiency. If there is a negative relationship between tariff rate and SSR in food-importing countries or a positive relationship between the tariff rate and SSR in exporting countries, it can be an evidence of the polarization of food self-sufficiency, which means that domestic food supply in the importing countries has no longer developed in a sustainable way.

The first objective of this paper is to measure the impact of tariff reduction on food SSR. Although there are empirical studies that tariff reduction leads to an increase in food production 
of exporting countries and an increase in consumption of importing countries, no study has examined the specific size of impacts on the food self-sufficiency. In this paper, we try to empirically test the fact that "tariff reduction has a negative effect on food SSR of importing countries", which is suggested by international trade theory. For this analysis, we build a theoretical model using the supply-demand framework for importing and exporting countries.

The second objective of the paper is to measure the magnitude of the effect of factors that shift food demand and supply curves, such as income or substitute prices, on food self-sufficiency. The relative comparison of the results for these measurements will reveal which factors are more important to the food SSR than the tariff rate. In this paper, to achieve this second objective, the elasticity of the food self-sufficiency rate with respect to the tariff rate is derived theoretically and its size is empirically calculated. In particular, this paper examines the influence of the factors affecting the sustainability of domestic food production in the country.

The Food and Agriculture Organization's (FAO's) broad range of food commodities includes whole edible food items, like grains (rice, wheat, and barley), as well as food items in other categories, like vegetables, fruit, meat, fish, milk, and milk products [28,29]. However, grain is regarded as more important than other food items, like meat or seafood, thus food self-sufficiency is usually defined in terms of the staple food crops, such as basic cereals and root crops [30,31]. Following this tradition, in this study, we only include grains in our food range, and then calculate the SSR with that limitation.

\section{Theoretical Discussion}

We define a country's grain SSR as the ratio of domestic grain production to overall domestic grain consumption, which is presented as $\frac{\operatorname{Production}\left(Q_{P}\right)}{\operatorname{Consumption}\left(Q_{C}\right)}$. The consumption $Q_{C}$ in this paper is calculated as [Production + Imports - Exports], following FAO [10] and Clapp [9].

Thus, we can say that the factors that affect grain production or consumption ultimately have an impact on the grain SSR. As a representative example, if tariff reduction occurs in a small importing country, in such a situation that there is no intra-industry trade, the amount of imported grain will increase, domestic production will decrease, and therefore it will cause a decrease in the grain SSR in that country. However, this discussion is valid only under the controlled supply and demand. In other words, a country's grain SSR can be affected by other factors, such as world grain price [29] and population growth [28] etc.

The Overseas Development Institute (ODI) [2], FAO [29], Organization for Economic Co-operation and Development (OECD) [32], and Brooks [33] discuss the influence of the increase in the world grain price on the food consumption and production. According to them, in the long term, this increase will negatively affect the overall consumption and production of a poor country. In addition, Sung et al. [7] insist that the increase in the world grain price can seriously influence the grain production and consumption in the importing country, such as Korea. These researches clearly suggest that world grain price must be included as a main control variable in the empirical analyses.

In order to make the discussion relatively simple, we start with the assumption that there is no trade cost between importing and exporting countries other than tariff. The second assumption for the theoretical discussion is that the importer and exporter both are small countries, thus the world grain price is given as an exogenous variable. With these assumptions, we can examine how the change in tariff, world grain price, and the shifters of supply and demand affects the grain SSR for importing and exporting countries.

The components of SSR, such as consumption $\left(Q_{C}\right)$ and production $\left(Q_{P}\right)$, are determined by a supply and demand curve, which means the SSR can be defined using the framework of a supply-demand model. The supply of domestic production and demand in the importing country are presented as:

$$
\begin{gathered}
Q_{I P}=S_{I}\left(P_{I}, S_{S I}\right) \\
Q_{I C}=D_{I}\left(P_{I}, S_{D I}\right),
\end{gathered}
$$


where $Q_{I P}$ is the importing country's domestic supply, $P_{I}$ is the imported grain price which is the same as world price $\left(P_{W}\right)$ multiplied by 1 plus tariff rate (i.e., $\left.P_{W}(1+t)\right), S_{S I}$ is the supply shifter, $Q_{I C}$ is the importing country's domestic demand, and $S_{D I}$ is the demand shifter.

Supply and demand in exporting country can be defined as:

$$
\begin{aligned}
& Q_{E P}=S_{E}\left(P_{W}, S_{S E}\right) \\
& Q_{E C}=D_{E}\left(P_{W}, S_{D E}\right)
\end{aligned}
$$

where $Q_{E P}$ is the production, $S_{S E}$ is the supply shifter, $Q_{E C}$ is the domestic demand, and $S_{D E}$ is the demand shifter.

Figure 1 depicts the influences of changes in international price, supply and demand shifters in the framework discussed using Equations (1)-(4). If the world grain price is $P_{W 1}$, the importer's production and consumption will be determined at the crossing points of the demand curve, $D_{I}$, the supply curve, $S_{I}$, and the domestic price of imported grain $P_{W 1}\left(1+t_{0}\right)$. The crossing points are $Q_{I C 1}$ and $Q_{I P 1}$, therefore the importer's grain SSR will be $\frac{Q_{I P 1}}{Q_{I C 1}}$. In the exporter's case, the crossing points of the demand curve, $D_{E}$, and the supply curve, $S_{E}$, with the world grain price, $P_{W 1}$, are the levels of the consumption and production. These points are $Q_{E C 1}$ and $Q_{E P 1}$, and we can present the exporter's grain SSR as $\frac{Q_{E P 1}}{Q_{E C 1}}$.

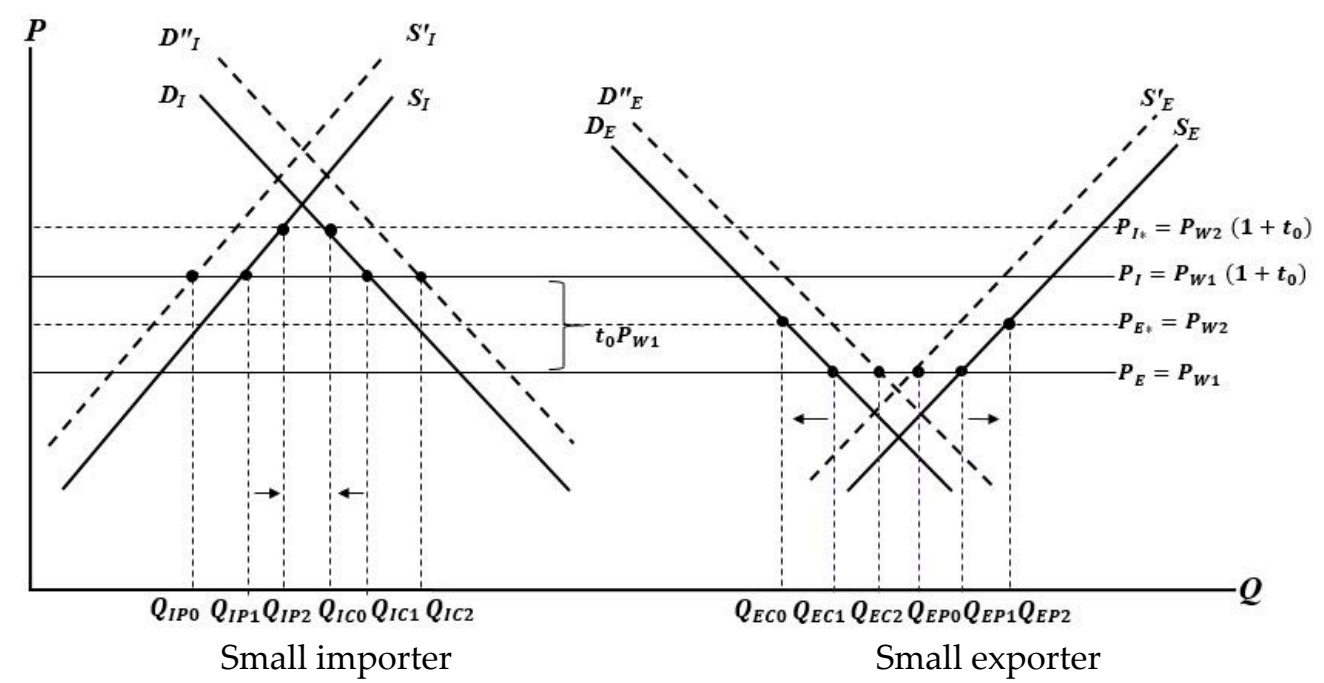

Figure 1. Effects of the changes in supply and demand shifters on grain self-sufficiency rate (SSR).

If the world grain price increases from $P_{W 1}$ to $P_{W 2}$, the importer's production will increase to $Q_{I P 2}$ and consumption will decrease to $Q_{I C 0}$; thus, the importer's grain SSR will increase to $\frac{Q_{I P 2}}{Q_{I C 0}}$. Likewise, an increase in the world grain price will cause an increase in the exported price, which means that the exporter's production increases to $Q_{E P 2}$ and consumption decreases to $Q_{E C 0}$. This will increase the exporter's SSR to $\frac{Q_{E P 2}}{Q_{E C O}}$. Consequently, an increase in the world grain price causes an increase in grain SSR of both the importer and exporter.

Meanwhile, if the importer's demand curve shift from $D_{I}$ and $D_{I}{ }^{\prime \prime}$ due to the change in the demand shifter, the shifting of the demand curve causes the importer's consumption to increase to $Q_{I C 2}$, but production remains constant; thus, the importer's SSR decreases from $\frac{Q_{I P 1}}{Q_{I C 1}}$ to $\frac{Q_{I P 1}}{Q_{I C 2}}$. Similarly, the exporter's consumption increases to $Q_{E C 2}$, but production remains constant; thus, the exporter's SSR decreases from $\frac{Q_{E P 1}}{Q_{E C 1}}$ to $\frac{Q_{E P 1}}{Q_{E C 2}}$, if the exporter's demand curve shift from $D_{E}$ to $D_{E}{ }^{\prime \prime}$. As a result, the right shifting of the demand curve causes a decrease in the grain SSR to both the importer and exporter.

If the supply curves of both the exporter and importer shift to the left due to the change in the supply shifter such as an increase in input price, the importer's production decreases from $Q_{I P 1}$ to 
$Q_{I P 0}$, and the exporter's production decreases from $Q_{E P 1}$ to $Q_{E P 0}$. Thus, the left shifting of the supply curve causes a decrease in the SSR from $\frac{Q_{I P 1}}{Q_{I C 1}}$ to $\frac{Q_{I P 0}}{Q_{I C 1}}$ and $\frac{Q_{E P 1}}{Q_{E C 1}}$ to $\frac{Q_{E P 0}}{Q_{E C 1}}$, for the importer and exporter, respectively (all of the discussions regarding Figure 1 are based on the strong assumption that there is no endogeneity problem related to world grain price. In other words, it assumes that the world grain price is treated as truly exogenous variable).

The effects of tariff reduction on the grain SSR are presented in Figure 2. If the importer reduces its tariff rate from $t_{0}$ to $t_{1}$, the imported grain price will decrease from $P_{I}$ to $P_{I^{*}}$, and importer's production and consumption will be determined at the crossing point where the demand and supply curves meet with $P_{I *}$. Because the importer's production decreases to $Q_{I P 0}$ and consumption increases to $Q_{I C 2}$, the importer's SSR will decrease. However, in the exporter's case, if its trading partner's tariff rate decreases from $t_{o}$ to $t_{1}$, the exported grain price will increase from $P_{E}$ to $P_{E *}$. Then, production and consumption will shift from $Q_{E P 1}$ to $Q_{E P 2}$ and $Q_{E C 1}$ to $Q_{E C 0}$, respectively. Thus, the exporter's SSR will increase from $\frac{Q_{E P 1}}{Q_{E C 1}}$ to $\frac{Q_{E P 2}}{Q_{E C O}}$.

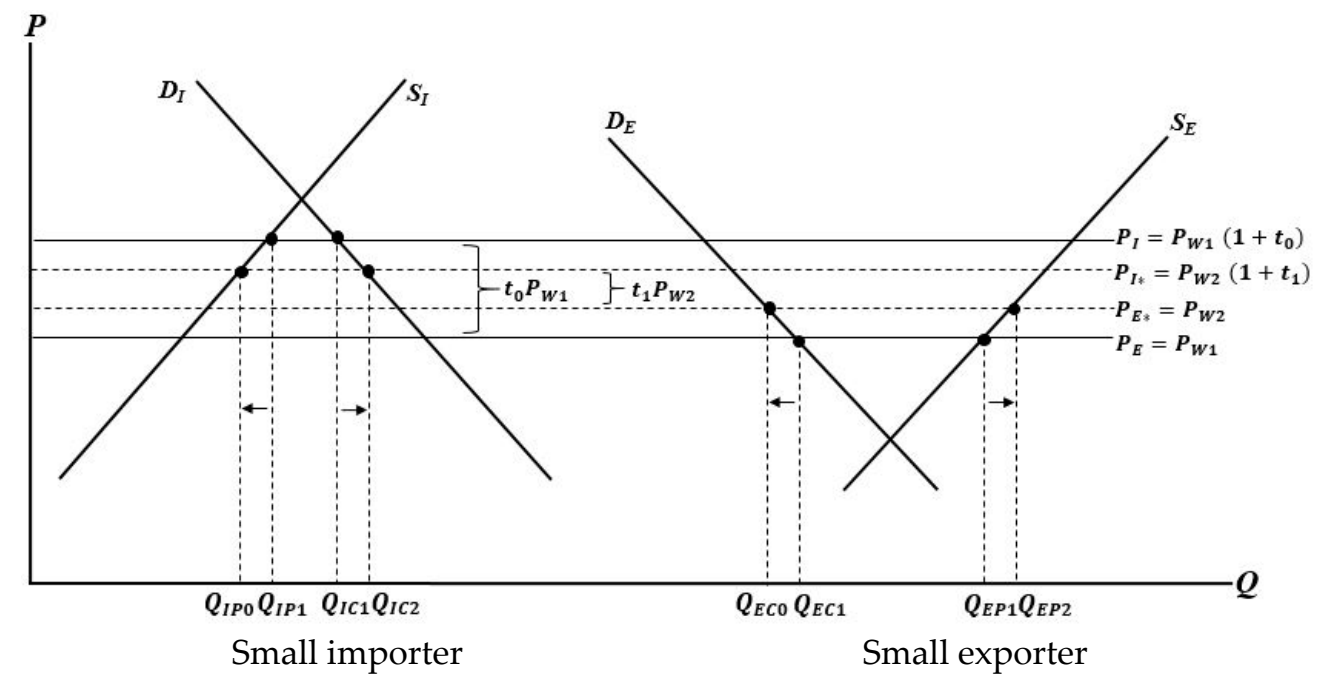

Figure 2. Effects of a tariff reduction on grain SSR.

The derivation of the "elasticity of SSR with respect to tariff rate", one of the research objectives of this paper, depends on what type of functional form of the empirical model is applied. Therefore, this elasticity is discussed in detail in the section describing the empirical model.

In the empirical estimations for testing the theoretical expectations discussed using Figures 1 and 2, we select the control variables of demand and supply shifters, based on the previous studies. Gerbens-Leenes et al. [34] and Tilman et al. [21] discuss the effect of economic growth on food consumption and production, by examining the change in the food supply and consumption pattern caused by economic growth (or increase in income). Ahn and Han [18] and Park et al. [5] insist that increasing income can be a threat to food security on the consumption side. Furthermore, Park et al. [35] predict that a continuous increase in the population will cause an increase in consumption and an excess demand over production. When considering these studies, we add income and population growth as representative demand shifters. Kim et al. [30] discuss that an increase in the production cost, caused by an increase in the fertilizer price, will lead to a decrease in food production. Trostle [35] asserts that increasing world input cost, like an increase in the price of fertilizer, causes a decrease in production. Reflecting these studies we select fertilizer price as a representative supply shifter. We also include meat price in the empirical equations in order to capture the substitution effect between grain and meat. Among the supply and demand shifters discussed above, the factors affecting the sustainability of domestic production of grain include international grain prices, fertilizer prices, and tariffs in importing countries. Fertilizer prices are expected to have 
a negative correlation with grain production, and international grain prices and import tariffs are expected to have a positive correlation with grain production for the importing countries.

\section{Data and Methodology}

\subsection{Data}

The measurement of SSR can be divided into four categories with data types: quantity-based food SSR, staple-grain-based SSR, calorie-based SSR, and value-amount-based SSR. This study uses the quantity-based SSR because it is an appropriate method for defining grain SSR, considering the data availability over the countries. FAO's statistics data is used for calculating the grain SSR for each country. This grain data includes production, stock from last year, import, and consumption of rice, wheat, maize, barley, and mixed grains. We use the annual data for 150 countries from 1995 to 2011, for which we could obtain data for the entire countries (the list of 150 countries is in the Appendix A).

The summary statistics for the variables used in our estimation are shown in Table 1. We use data from the World Bank for the world grain price, GDP per capita, population, world fertilizer price, and world beef price. The average SSR for the date period is calculated to be 0.6924 . The average price of rice is the highest as $\$ 365.91 / \mathrm{Mt}$ and maize price is the lowest as $\$ 151.51 / \mathrm{Mt}$. The average GDP per capita is $\$ 8805.79$ for the countries included in the analysis. A tariff rate applied by importing countries is $9.7901 \%$ on average, which is slightly higher than the one faced by exporting countries when they export grains to the partner importing countries. The average beef price is $\$ 2.68 / \mathrm{kg}$ during the data period. All of the price data is real price, in which inflation rate is reflected. For the world grain price data, we select Thai rice, U.S. hard red winter wheat and maize, which are the typical grain products traded in the international market [36]. We use the price of diammonium phosphate (DAP) fertilizer as the representative fertilizer price.

Table 1. Summary statistics of variables.

\begin{tabular}{ccc}
\hline Variables & Average & Standard Deviation \\
\hline Grain SSR & 0.69240 & 0.5352 \\
World rice price (\$/Mt) & 365.91 & 117.34 \\
World wheat price (\$/Mt) & 205.38 & 50.22 \\
World maize price (\$/Mt) & 151.51 & 42.89 \\
GDP per capita (\$) & 8805.79 & $13,233.3$ \\
Population & $40,800,000$ & $141,000,000$ \\
World DAP price $(\$ / \mathrm{Mt})$ & 330.69 & 192.31 \\
Importer's domestic tariff $(\%)$ & 9.7901 & 16.90 \\
Exporter's trade partner's tariff $(\%)$ & 9.3477 & 1.11 \\
World beef price $(\$ / \mathrm{kg})$ & 2.68 & 0.47 \\
\hline
\end{tabular}

Notes: Mt denotes metric ton.

We separate 150 countries into exporters and importers; the former refers to a country with over $100 \%$ grain self-sufficiency during the data period in the analysis, and the latter refers to a country with under $100 \%$ grain self-sufficiency. We use the "effectively applied tariff" data of the World Bank's World Integrated Trade Solution (WITS) database. As shown in Table 1, the importer's domestic tariff refers to the tariff on imported grains in the importing country. On the contrary, the exporter's trade partner's tariff refers to the applied tariff by the exporter's trade partners (i.e., importers). In exporting, the exporter should consider the tariff on exporting products; thus, the exporter's domestic tariff is unimportant in this study. However, the WITS's data only includes the importer's domestic tariff. Therefore, to find the tariff of the exporter's trade partner, we use the average value of the importer's domestic tariff $\left(t_{E}=\frac{\sum_{i=1}^{n} t_{i}}{n}\right.$, where $t_{E}$ is the average of tariffs from the exporter's trading partners, $t_{i}$ is the importer $i^{\prime}$ 's domestic tariff, and $n$ is the number of importers). 


\subsection{Empirical Estimation}

For estimating the effect of tariff reduction on the grain SSR, we construct a balanced panel data of 150 countries over the 17 years. The discussions using Figures 1 and 2 are based on the strong assumption of exogenous world grain price. However, international price is likely to be influenced by large exporting or importing countries, which may cause a problem of endogeneity between the grain SSR as a world grain price. In other words, the world grain price causes a change in the grain SSR, but also that there is a possibility of reverse causality, which means the grain SSR can cause a change in the world grain price. This endogeneity problem may cause a biased estimator.

The endogeneity problem can be solved efficiently by including the lagged level of the dependent variable, without employing another instrument variable in the panel data estimation. However, if we include the lagged level of the dependent variables as the explanatory variables, we cannot use the fixed and random effect models. Therefore, we apply a dynamic panel model that applies the Generalized Method of Moments(GMM) approach [37-39]. Dynamic panel models are useful under the condition that the dependent variable depends on its own past realizations [39]. In this study, we use the system GMM estimator, proposed by Arellano and Bover [40] as well as Blundell and Bond [37]. The system GMM estimation approach that is applied for importing countries is set as Equation (5):

$$
\begin{gathered}
\ln S S R_{N T}=\alpha+\beta_{1} \ln S S R_{N T-1}+\beta_{2} \ln P_{W, T}+\beta_{3} \ln P_{W, T-1}+\beta_{4} \ln G D P_{N T} \\
+\beta_{5} \ln P_{o p_{N T}}+\beta_{6} \ln P_{F, T}+\beta_{7}\left(1+\operatorname{Tariff}_{N T}\right)+\beta_{8} \ln P_{S, T}+\beta_{9} \text { Food crisis }+u_{N}+\epsilon_{N T}
\end{gathered}
$$

where $S S R_{N T}$ and $S S R_{N T-1}$ are the grain SSR at $T$ and its lagged level at $T-1 ; P_{W, T}$ and $P_{W, T-1}$ are the current and lagged world grain prices (we include both because they may have different effects on the grain SSR; the former reflects the immediate effects, whereas the latter reflects the accumulated effects of the grain price [28]). GDP is the GDP per capita; Pop is the population; $P_{F}$ is the world fertilizer price; Tariff is the importer's domestic tariff rate; $P_{S}$ is the world beef price as a substitute price; $u$ is a country fixed effect; and, $\varepsilon$ is an error term. For capturing the influence of the food crisis in 2008, we add a dummy variable of Food crisis.

For running the regression based on whole countries including exporting and importing countries, empirical Equation (6) is applied.

$$
\begin{gathered}
\ln S S R_{N T}=\alpha+\beta_{1} \ln S S R_{N T-1}+\beta_{2} \ln P_{W, T}+\beta_{3} \ln P_{W, T-1}+\beta_{4} \ln G D P_{N T} \\
+\beta_{5} \ln \text { Pop }_{N T}+\beta_{6} \ln P_{F, T}+\operatorname{Import} \cdot \beta_{7} \ln \left(1+\text { Tariff } f_{N T}\right) \\
+ \text { Export } \cdot \beta_{8} \text { Trade Partner's Tariff } f_{N T}+\beta_{9} \ln P_{S, T}+\beta_{10} \text { Food crisis }+u_{N}+\epsilon_{N T}
\end{gathered}
$$

where Trade Partner's Tariff is the tariff for exporter's trade partner.

As this study uses log values on the dependent variables and explanatory variables, all coefficient estimates are in the form of elasticity. However, estimated coefficient on $\beta_{7}$ in empirical Equation (5) implies $\frac{\% \Delta S S R}{\% \Delta(1+t)}$; in other words, we can interpret this with the influence of the proportional change in $1+t$ on that in the grain SSR. However, our interest is not the $1+t$; rather, we want to find the elasticity of the grain SSR with respect to tariff rate $t$ (i.e., $\varepsilon=\frac{\% \Delta S S R}{\% \Delta t}$ ). To derive this, we apply the calculation procedure as follows:

$$
\begin{gathered}
\beta_{7}=\frac{\partial S S T}{\partial(1+t)} \frac{1+t}{S S R} \\
\beta_{7} \frac{\partial(1+t)}{\partial t} \frac{t}{1+t}=\frac{\partial S S R}{\partial(1+t)} \frac{1+t}{S S R} \frac{\partial(1+t)}{\partial t} \frac{t}{1+t} \\
\beta_{7} \frac{t}{1+t}=\frac{\partial S S R}{\partial t} \frac{t}{S S R} \quad \text { therefore } \varepsilon=\beta_{7} \frac{t}{1+t}
\end{gathered}
$$

We need to test the validity of the instrument variables when applying the system GMM estimation. The required test is for checking the exogeneity of instrument variables. In other words, 
the dependent variable's lagged value, which we use as an instrument variable, should have a first autocorrelation, but not a second, with the residuals. We use the Arellano-Bond's Autocorrelation of order 1 and 2 (AR (1)) and AR (2)) tests for this checking. We additionally conduct a Hansen test for verifying the over-identification problem [3].

\section{Empirical Results}

\subsection{Estimation Results for the Importing Countries}

Table 2 reports the estimation results for the variables that affect the importing countries' grain SSR. Once getting a system GMM estimator, we should check our validity for applying the model. First, we check the significance of the coefficients of the lagged dependent variable. This variable is significant at the $1 \%$ level, so we can conclude that it is proper to use a dynamic panel model. According to Models (1)-(3), if last year's grain SSR is high, the present value of the grain SSR is also high. This implies that there is a large degree of persistence of the grain SSR. One country's SSR is decided by economic, cultural, environmental, and climatic conditions. Thus, the SSR cannot change suddenly in the short term, so we can say the grain SSR is strongly time-persisting. This is proven by the strong correlation between the past and present grain SSRs. System GMM is an estimator that uses the instrument variables; therefore, we need to know the validity of the instrument variables in the model. The null hypotheses of "no second-order autocorrelation" (AR (2) test) and "over-identification of all instruments" (Hansen test) cannot be rejected. These test results confirm the validity of the instruments used.

Table 2. Estimation results for importers.

\begin{tabular}{|c|c|c|c|}
\hline Variables & $\begin{array}{l}\text { Model (1) } \\
\text { Rice Price Is Used } \\
\text { for Representing } \\
\text { World Grain Price }\end{array}$ & $\begin{array}{c}\text { Model (2) } \\
\text { Wheat Price Is Used } \\
\text { for Representing } \\
\text { World Grain Price }\end{array}$ & $\begin{array}{l}\text { Model (3) } \\
\text { Maze Price Is Used } \\
\text { for Representing } \\
\text { World Grain Price }\end{array}$ \\
\hline Lagged SSR & $0.470^{* * *}(0.056)$ & $0.479^{* * *}(0.056)$ & $0.475^{* * *}(0.059)$ \\
\hline World rice price & $0.0728(0.160)$ & & \\
\hline Lagged world rice price & $-0.0369(0.095)$ & & \\
\hline World wheat price & & $0.310^{* * *}(0.104)$ & \\
\hline Lagged world wheat price & & $-0.169(0.141)$ & \\
\hline World maize price & & & $0.262 * * *(0.074)$ \\
\hline Lagged world maize price & & & $-0.0620(0.068)$ \\
\hline GDP per capita & $-1.196^{* *}(0.546)$ & $-0.977^{* *}(0.448)$ & $-0.989 *(0.514)$ \\
\hline Population & $1.875^{* *}(0.926)$ & $2.224^{* *}(1.002)$ & $2.075^{* *}(0.833)$ \\
\hline DAP fertilizer price & $0.239(0.171)$ & $0.176(0.139)$ & $0.130(0.164)$ \\
\hline Importer's domestic tariff $(\alpha)$ & $2.766^{* *}(1.130)$ & $2.643^{* *}(1.235)$ & $3.097 * *(1.330)$ \\
\hline World beef price & $-0.551(0.435)$ & $-0.861 *(0.520)$ & $-0.719 *(0.405)$ \\
\hline World food crisis & $-0.220^{* *}(0.101)$ & $-0.295^{* * *}(0.110)$ & $-0.228 *(0.124)$ \\
\hline AR (1) test & 0.000 & 0.000 & 0.000 \\
\hline AR (2) test & 0.090 & 0.109 & 0.122 \\
\hline Sargan test & 0.000 & 0.000 & 0.000 \\
\hline Hansen test & 0.341 & 0.433 & 0.401 \\
\hline Observations & 1949 & 1949 & 1,949 \\
\hline Number of groups & 132 & 132 & 132 \\
\hline
\end{tabular}

Notes: Standard errors are in parentheses. ${ }^{* * *} p<0.01,{ }^{* *} p<0.05$, and ${ }^{*} p<0.1$.

In Table 2, we use the world rice, wheat, and maize prices as the representative grain prices in Models (1), (2), and (3), respectively. In Model (1), when the world rice price increases, the grain SSR also increases, but it is not statistically significant. However, other grains in other models show significant results; thus, it seems that the world rice price cannot be the representative price of world grain. If the GDP per capita increases by $1 \%$, the importer's grain SSR is estimated to decrease by $1.2 \%$. The world food crisis in 2008 is estimated to cause a $0.2 \%$ decrease in the importer's grain SSR. 
In Model (2), we use the world wheat price as the representative grain price, and we obtain a statistically and positively significant result for this variable. This corresponds with our theoretical discussions, as well as the findings of previous studies. An increase in the world wheat price by $1 \%$ is estimated to cause a $0.3 \%$ increase in the grain SSR. This implies that, ceteris paribus, worldwide grain price has a positive effect in achieving the sustainability of domestic grain production for the importing countries.

Other variables, such as the GDP per capita and world beef price, show statistically significant results. It is implied that when these variables increase, the importer's grain SSR will decrease, which also corresponds with our theoretical expectation.

In Model (3), we use the world maize price; when it increases by $1 \%$, the importer's grain SSR increases by $0.26 \%$. Similar to the results of Model (2), the GDP per capita and world beef price are also significant.

From the estimation results in Table 3, we can confirm that the external shock of the world food crisis in 2008, which was caused by a spike in grain prices, led to a decrease in the importer's grain SSR. This crisis caused a serious food deficiency in not only poor countries, but in the whole world as well. Our results empirically prove that the grain SSR of importing countries was weakened by the world food crisis.

Table 3. Importer's elasticity of SSR with respect to tariff rate.

\begin{tabular}{|c|c|c|c|c|c|}
\hline & & \multirow{2}{*}{ Average Tariff $(t)$} & \multicolumn{3}{|c|}{ Average of the Elasticity of SSR to the Tariff $\left(\varepsilon_{t}\right)$} \\
\hline & & & Model (1) & Model (2) & Model (3) \\
\hline \multicolumn{2}{|c|}{ Importer } & 0.102 & 0.257 & 0.245 & 0.287 \\
\hline \multirow{2}{*}{ OECD } & Member & 0.143 & 0.346 & 0.330 & 0.387 \\
\hline & Non-member & 0.104 & 0.261 & 0.250 & 0.292 \\
\hline \multirow{6}{*}{ Year } & 2000 & 0.114 & 0.282 & 0.270 & 0.316 \\
\hline & 2002 & 0.106 & 0.266 & 0.254 & 0.298 \\
\hline & 2004 & 0.108 & 0.269 & 0.257 & 0.302 \\
\hline & 2006 & 0.098 & 0.247 & 0.236 & 0.277 \\
\hline & 2008 & 0.091 & 0.232 & 0.221 & 0.259 \\
\hline & 2010 & 0.094 & 0.237 & 0.227 & 0.266 \\
\hline
\end{tabular}

Table 3 presents the derived elasticity of the grain SSR with respect to $t$ (i.e., $\varepsilon$ in Equation (9)). As indicated, if the importer's domestic tariff rate increases by $1 \%$, then the grain SSR will increase by $0.26 \%$ in Model (1), $0.24 \%$ in Model (2), and $0.29 \%$ in Model (3) on average for the entire data period, which suggests that the elasticity of grain SSR with respect to tariff rate is inelastic. The positive correlation between tariff rates and SSR implies that an increasing tariff leads to a more domestic grain production, which may lead to an achievement of the sustainability in conserving the agricultural land.

We compare the elasticity for the OECD member and non-member countries. If the importer is an OECD member, the elasticity is slightly higher than that of a non-member importer. We also use the importer's annual average tariff for measuring the elasticity of grain SSR in 2000, 2002, 2004, 2006, 2008 , and 2010. There are no large gaps among these years. Interestingly, the lowest elasticity of grain SSR appears in 2008. This phenomenon can be interpreted as a side effect of 2008's world food crisis. Except for the results in 2008, calculated elasticities from all three models show a decreasing trend during the data period. This suggests that the degree of the response of SSR to tariff rate has been reduced. These results are due to the fact that the marginal effect of tariff reduction on SSR becomes smaller because the trade liberalization (i.e., tariff reduction) has progressed further as time goes by.

According to the value of the average tariff, the changing degree of the grain SSR shows different results. However, in Models (1)-(3), an increase in tariff rate is estimated to cause an improvement of the importer's grain SSR in common. This suggests that the decrease in the importer's tariff negatively affects the importer's grain SSR. 
When comparing the coefficients on demand-supply shifters in Table 2 with the elasticities calculated in Table 3 yields interesting results. The estimated coefficients on demand and supply shifters in Table 2 are the elasticities themselves. Therefore, we can say that impact of population on grain SSR is the largest and that of GDP per capita is the second largest across all three models, in terms of the absolute values of the estimated elasticities. Influence of world grain price is estimated to be the lowest. However, the elasticities of SSR with respect to world grain price are greater than those with respect to tariff rate. This implies that the tariff rate significantly influences grain SSR, but its impact is relatively small compared to the shifters of grain demand and supply.

\subsection{Estimation Results for the Overall Countries}

Table 4 shows the estimation results for all 150 countries. Based on the $p$-values for the AR (1) and (2) tests, we can confirm the presence of first-order autocorrelation, but no second-order autocorrelation. We find that there is no over-identifying problem from the result of the Hansen test.

Table 4. Estimation results for all countries.

\begin{tabular}{|c|c|c|c|}
\hline Variables & $\begin{array}{l}\text { Model (1) } \\
\text { Rice Price Is Used } \\
\text { for Representing } \\
\text { World Grain Price }\end{array}$ & $\begin{array}{c}\text { Model (2) } \\
\text { Wheat Price Is Used } \\
\text { for Representing } \\
\text { World Grain Price }\end{array}$ & $\begin{array}{c}\text { Model (3) } \\
\text { Maze Price Is Used } \\
\text { for Representing } \\
\text { World Grain Price }\end{array}$ \\
\hline Lagged SSR & $0.458^{* * *}(0.062)$ & $0.472^{* * *}(0.0606)$ & $0.468^{* * *}(0.0622)$ \\
\hline World rice price & $0.0866(0.150)$ & & \\
\hline Lagged world rice price & $-0.0343(0.0970)$ & & \\
\hline World wheat price & & $0.286^{* * *}(0.106)$ & \\
\hline Lagged world wheat price & & $-0.157(0.125)$ & \\
\hline World maize price & & & $0.260^{* * *}(0.0760)$ \\
\hline Lagged world maize price & & & $-0.0461(0.0601)$ \\
\hline GDP per capita & $-1.225^{* *}(0.548)$ & $-1.008^{* *}(0.449)$ & $-1.000^{* *}(0.509)$ \\
\hline Population & $1.810^{* *}(0.873)$ & $2.118 * *(0.952)$ & $1.968^{* *}(0.816)$ \\
\hline DAP fertilizer price & $0.223(0.155)$ & $0.190(0.142)$ & $0.128(0.164)$ \\
\hline Importer's domestic tariff & $2.774^{* * *}(1.037)$ & $2.688^{* *}(1.177)$ & $3.004^{* *}(1.235)$ \\
\hline Exporter's partner's tariff & $-0.0463(1.478)$ & $-0.681(1.371)$ & $0.159(1.512)$ \\
\hline World beef price & $-0.489(0.371)$ & $-0.823 *(0.471)$ & $-0.666 *(0.373)$ \\
\hline World food crisis & $-0.204^{* *}(0.101)$ & $-0.289^{* * *}(0.110)$ & $-0.217 *(0.124)$ \\
\hline AR (1) test & 0.000 & 0.000 & 0.000 \\
\hline AR (2) test & 0.070 & 0.115 & 0.085 \\
\hline Sargan test & 0.000 & 0.000 & 0.000 \\
\hline Hansen test & 0.264 & 0.345 & 0.251 \\
\hline Observations & 2139 & 2139 & 2139 \\
\hline Number of groups & 145 & 145 & 145 \\
\hline
\end{tabular}

Notes: Standard errors are in parentheses, ${ }^{* * *} p<0.01,{ }^{* *} p<0.05$, and ${ }^{*} p<0.1$.

Model (1) uses the world rice price as a representative grain price, and the result is the same as the one in Table 4: the world rice price does not affect the world grain SSR. Model (2) presents that a $1 \%$ increase in the world wheat price will generate a $0.29 \%$ rise in the level of the world's grain SSR, which is significant at the $1 \%$ level. In Model (3), a $1 \%$ increase in the world maize price will cause a $0.26 \%$ rise in the level of the world's grain SSR. Estimated results suggest that the world grain prices seem to have the largest effect on the world grain SSR than other variables. However, the rice, wheat, and maize prices in past years have no significant effect on the world's grain SSR.

The importer's tariff and grain SSR show a positive correlation, and the exporter's grain SSR and trade partner's tariff SSR show a negative correlation. These estimation results correspond to our theoretical discussion, but in the case of the exporter, the estimated coefficients are not statistically significant. The GDP per capita, world beef price, and food crisis in 2008 are estimated to cause the decrease in the world's grain SSR. 
We expect that there will be a negative relationship between the population and grain SSR, but the estimated coefficients on population are consistently positive and statistically significant. This is the result of the cross-sectional effect that offsets the time-series effect. In terms of time-series data, population growth will cause a decrease in the grain SSR as time passes. However, according to the cross-sectional effect, the most populous countries have higher grain SSR because they have higher levels of consumption and production. In our panel data analysis, the cross-sectional effect is large enough to offset the time-series effect. Thus, all of the estimation results show that the coefficients in the population have a consistently positive effect on the grain SSR.

\section{Summary and Conclusions}

This paper investigates the effect of a tariff reduction on the world's grain self-sufficiency, which is a main component in defining the food security, especially from the perspective of food-importing countries.

We define grain self-sufficiency as domestic production divided by domestic consumption. Prior to the empirical estimation, we develop a theoretical model using a supply-demand framework, with importer and exporter classifications. Then, we theoretically discuss each variable's effect on the grain SSR. According to the results, the world grain price and SSR are positively correlated, but the GDP per capita, population, input price, and substitute price show negative results. The notable result is that a change in the importer's domestic tariff has a different influence on the importer than it does on the exporter. The importer's domestic tariff reduction will cause a decrease in the importer's grain SSR, but under the equal conditions, an increase in the exporter's grain SSR.

In this study, we especially focus on the tariff variable. The domestic tariff for the importer and importer's grain SSR are positively correlated, while the exporter's tariff and grain SSR are negatively correlated; however, the result of the exporter's case is statistically insignificant. This means that the tariff reduction has a negative effect only on the importer's grain SSR. Therefore, the results based on our theoretical and empirical models support the perspective that market expansion through tariff reduction will have a negative effect on the importer's food SSR. The findings from this study may serve as a useful reference for most food-importing countries that want to implement policies for improving food SSR.

This paper, however, presents some limitations and future challenges to overcome. First, we need to expand the "food" category to include not only grains, in order to analyze all of the food items like meat, seafood, and vegetables. Second, we should have a precise and distinguishable standard in the process of classifying 150 countries into importers and exporters. The inequality and polarization of the world's food SSR, as Jeon and Ahn [27] discussed, seem to be closely related to the determinants that are used in this study. Therefore, further research is required to analyze the factors affecting the inequality and polarization of the food SSR in the world.

While tariff reduction has the advantage of allowing consumers to consume more food at lower prices, it also has the side effect of shrinking sustainable food production in the country. The stable production and supply of food is essential to the sustainable growth of an economy, and this is empirically proven by the fact that most developed countries maintain a high level of food self-sufficiency. In this context, analyzing the relationship between food SSR and sustainable economic growth is also an important issue that could be the subject of a future research.

Acknowledgments: Supported by a Korea University Grant.

Author Contributions: Younghyeon Jeon analyzed the data; Byeong-il Ahn wrote the paper.

Conflicts of Interest: The authors declare no conflict of interest. 


\section{Appendix A}

Table A1. List of 150 countries.

\begin{tabular}{ll}
\hline \multicolumn{1}{c}{ Importer } & Exporter \\
\hline Afghanistan, Albania, Algeria, Angola, Antigua and Barbuda, Armenia, Austria, Bahamas, & \\
Bangladesh, Barbados, Belarus, Belize, Benin, Bolivia (Plurinational State of), Botswana, & \\
Brazil, Brunei, Darussalam, Bulgaria, Burkina, Faso ,Cambodia, Cameroon, Central African & \\
Republic, Chad, Chile, China, Colombia, Congo, Costa Rica, Côte d'Ivoire, Croatia, Czech & Argentina, \\
Republic, Cuba, Cyprus, Democratic People's Republic of Korea, Denmark, Djibouti & Australia, \\
Dominica, Dominican Republic, Ecuador, Egypt, El Salvador, Estonia, Ethiopia, Fiji, & Canada, \\
Finland, Gabon, Gambia, Ghana, Greece, Grenada, Guatemala, Guinea, Guinea-Bissau, & France \\
Haiti, Honduras, India, Indonesia, Iran (Islamic Republic of), Ireland, Israel, Italy, Jamaica, & Germany, \\
Japan, Jordan, Kazakhstan, Kenya, Kuwait, Lao, People's Democratic Republic Lebanon, & Guyana, \\
Lesotho, Liberia, Libya, Lithuania, Madagascar, Malawi, Malaysia, Maldives, Mali, Malta, & Paraguay, \\
Mauritania, Mauritius, Mexico, Mongolia, Morocco, Mozambique, Myanmar, Namibia, & Sweden \\
Nepal, Netherlands, New Caledonia, New Zealand, Nicaragua, Niger, Nigeria, Norway, & Thailand, \\
Oman, Pakistan, Panama, Peru, Philippines, Poland, Portugal, South Korea, Romania, & USA, \\
Rwanda, Saint Vincent and the Grenadines, Sao Tome and Principe, Saudi Arabia, Senegal, & Uruguay, \\
Sierra Leone, Solomon Islands, South Africa, Spain, Sri Lanka, Sudan, Suriname, & Vietnam, \\
Swaziland, Switzerland, Syrian Arab Republic, Tajikistan, Timor-Leste, Togo, Trinidad and & Hungary \\
Tobago, Tunisia, Turkey, Uganda, United Arab Emirates, United Kingdom, United & \\
Republic of Tanzania, Vanuatu, Venezuela, Yemen, Zambia, Zimbabwe, Russian & \\
Federation, Ukraine, Uzbekistan & \\
\hline
\end{tabular}

\section{References}

1. Bezuneh, M.; Yiheyis, Z. Has Liberalization Improved Food Availability in Developing Countries? An Empirical Analysis. J. Econ. Dev. 2014, 39, 63-78.

2. Wiggins, S.; Levy, S. Rising Food Prices: A Global Crisis; Overseas Development Institute: London, UK, 2008.

3. Schuster, M.; Maertens, M. The Impact of Private Food Standards on Developing Countries' Export Performance: An Analysis of Asparagus Firms in Peru. World Dev. 2015, 66, 208-221. [CrossRef]

4. Seshamani, V. The Impact of Market Liberalization on Food Security in Zambia. Food Policy 1998, 23, 539-551. [CrossRef]

5. Park, D.G.; Seung, J.H. The Policy Subject of Reconsideration of Grain Self-Sufficiency; Korea Rural Economic Institute: Naju, Korea, 2013.

6. Seong, J.K. Global Food Crisis and Practical Proposal for Improvement of Korean Food Self-Sufficiency. Korea Rural Economic Institute. World Agric. 2013, 152, 65-90.

7. Sung, M.H.; Kim, T.H.; Woo, B.J.; Chai, S.H.; Seung, J.H.; Park, J.E. A Study on Developing Alternative Policy for Stably Securing Grains: Early Warning System and Overseas Agricultural Investment; Research Report C2008-42; Korea Rural Economic Institute: Naju, Korea, 2008.

8. Hailu, M.B. Food Security and Agricultural Trade Liberalization. In Society of International Economic Law (SIEL); Second Biennial Global Conference Paper; University of Barcelona: Barcelona, Spain, 2010.

9. Clapp, J. Food Security and Food Sovereignty: Getting Past the Binary. Dialog. Hum. Geogr. 2014, 4, $106-211$. [CrossRef]

10. FAO. FAO Statistical Yearbook 2012-World Food and Agriculture. Available online: http://www.fao.org/ docrep/015/i2490e/i2490e00.htm (accessed on 20 August 2017).

11. Goswami, P.; Nishad, S. Ensuring Self-Sufficiency and Sustainability in the Agrofood Sector. In Sustainability Challenges in the Agrofood Sector; Bhat, R., Ed.; John Wiley \& Sons, Ltd.: Chichester, UK, 2017.

12. Erokhin, V. Factors Influencing Food Markets in Developing Countries: An Approach to Assess Sustainability of the Food Supply in Russia. Sustainability 2017, 9, 1313. [CrossRef]

13. Di Corato, L.; Moretto, M.; Vergalli, S. Land conversion pace under uncertainty and irreversibility: Too fast or too slow? J. Econ. 2013, 110, 45-82. [CrossRef]

14. John, O.; Kennedy, S. Uncertainty, irreversibility and the loss of agricultural land: A reconsideration. J. Agric. Econ. 1987, 38, 75-80. 
15. Hodge, J. Uncertainty, Irreversibility and the Loss of Agricultural Land. J. Agric. Econ. 1984, 35, $191-202$. [CrossRef]

16. Little, L.; Buchan, J. Nursing Self Sufficiency/Sustainability in the Global Context; International Centre on Nurse Migration: Philadelphia, PA, USA, 2007.

17. Luan, Y.; Cui, X.; Ferrat, M. Historical trends of food self-sufficiency in Africa. Food Secur. 2013, 5, $393-405$. [CrossRef]

18. Ahn, B.I.; Han, D.B. Review of Various Viewpoints on Food Security and Policy Implications. Korea J. Agric. Manag. Policy 2012, 39, 815-840.

19. Hwang, Y.S. The Necessity, Possibility, and Policy Suggestion of Improving Food Self-Sufficiency Rate in Korea. J. Rural Dev. 2009, 17, 29-58.

20. O'Hagan, J.P. National self-sufficiency in food. Food Policy 1975, 1, 355-366. [CrossRef]

21. Tilman, D.; Balzer, C.; Hill, J.; Befort, B.L. Global Food Demand and the Sustainable Intensification of Agriculture. Proc. Natl. Acad. Sci. USA 2011, 108, 20260-20264. [CrossRef] [PubMed]

22. Suweis, S.; Carr, J.A.; Maritan, A.; Rinaldo, A.; D'Odorico, P. Resilience and reactivity of global food security. Proc. Natl. Acad. Sci. USA 2015, 112, 6902-6907. [CrossRef] [PubMed]

23. Puma, M.J.; Bose, S.; Young Chon, S.; Cook, B.I. Assessing the evolving fragility of the global food system. Environ. Res. Lett. 2015, 10, 024007. [CrossRef]

24. MacDonald, G.K.; Brauman, K.A.; Sun, S.; Carlson, K.M.; Cassidy, E.S.; Gerber, J.S.; West, P.C. Rethinking agricultural trade relationships in an era of globalization. BioScience 2015, 65, 275-289. [CrossRef]

25. Naylor, R.L.; Falcon, W.P. Food Security in an Era of Economic Volatility. Popul. Dev. Rev. 2010, 36, 693-723. [CrossRef] [PubMed]

26. Clapp, J. Food self-sufficiency: Making sense of it, and when it makes sense. Food Policy 2017, 66, 88-96. [CrossRef]

27. Jeon, Y.H.; Ahn, B.I. Analysis of the world's inequality and polarization of food self-sufficient rate. Korea. J. Agric. Econ. 2015, 56, 71-97.

28. FAO. Trade Reforms and Food Security: Conceptualizing the Linkages; FAO: Rome, Italy, 2003.

29. FAO. The State of Food Insecurity in the World: How Does International Price Volatility Affect Domestic Economies and Food Security; FAO: Rome, Italy, 2011.

30. Kim, Y.T.; Kim, B.R.; Lee, B.H.; Jun, I.S.; Yoon, J.Y.; Min, J.H.; Kim, J.S.; Song, J.K.; Kim, W.B.; Kim, J.H. Overseas Agricultural Development for Food Security(3/3); Research Report R646; Korea Rural Economic Institute: Naju, Korea, 2011.

31. Nguema, I.E.; Ella, G.A. Trade Liberalization and Food Security: For a New Green Revolution in Africa. J. Food Secur. 2014, 2, 42-50.

32. Organization for Economic Co-Operation and Development (OECD). Rising Food Prices: Causes and Consequences; OECD: Paris, France, 2008.

33. Brooks, J. Policy Coherence and Food Security: The Effects of OECD Countries' Agricultural Policies. Food Policy 2014, 44, 88-94. [CrossRef]

34. Gerbens-Leenes, P.W.; Nonhebel, S.; Krol, M.S. Food Consumption Patterns and Economic Growth. Increasing Affluence and the Use of Natural Resources. Appetite 2010, 55, 597-608. [CrossRef] [PubMed]

35. Trostle, R. Global Agricultural Supply and Demand: Factors Contributing to the Recent Increase in Food Commodity Prices. Available online: http:/ / usda.mannlib.cornell.edu/usda/ers/WRS/2000s/2008/WRS05-02-2008_Special_Report.pdf (accessed on 11 September 2017).

36. International Grains Council (IGC). Grain Market Report (GMR 460-29); IGC: London, UK, 2015.

37. Blundell, R.; Bond, S. Initial Conditions and Moment Restrictions in Dynamic Panel Data Models. J. Econ. 1998, 87, 115-143. [CrossRef]

38. Ha, W.; Yi, J.; Yuan, Y.; Zhang, J. The Dynamic Effect of Rural-to-Urban Migration on Inequality in Source Villages: System GMM Estimates from Rural China. China Econ. Rev. 2015, 37, 27-39. [CrossRef] 
39. Kripfganz, S.; Schwarz, C. Estimation of Linear Dynamic Panel Data Models with Time-Invariant Regressors; Working Paper Series (No. 1838); European Central Bank: Frankfurt, Germany, 2015; Available online: https:/ / www.ecb.europa.eu/pub/pdf/scpwps/ecbwp1838.en.pdf?80cfd12fbb83c262ab6ff954b3108c21 (accessed on 11 September 2017).

40. Arellano, M.; Bover, O. Another Look at the Instrumental Variable Estimation of Error-components Models. J. Econom. 1995, 68, 29-51. [CrossRef] 